\title{
A SAGA DAS "VIDAS NUAS" EM O MUNDO À SOLTA, DE FELIPE FORTUNA: UM ESTADO DE EXCEÇÃO PERMANENTE
}

\section{THE SAGA OF "VIDAS NUAS" EM O MUNDO À SOLTA BY FELIPE FORTUNA: A PERMANENT STATE OF EXCEPTION}

Luzimara de Souza Cordeiro'

Elizabete Gerlânia Caron Sandrini²

\begin{abstract}
RESUMO: $O$ propósito deste trabalho é empreender a análise de alguns poemas de 0 mundo à solta, de Felipe Fortuna, evidenciando reflexóes sociais neles implicadas, por meio da saga das "vidas nuas" (AGAMBEM, 2010), aquelas que vivem em estado de exceçăo permanente. Uma situaçăo de indivíduos em constante status de exclusăo, que sobrevivem na fronteira entre o humano e o năo-humano, e têm as suas existências suspensas de direitos fundamentais. Assim, a abordagem de três poemas - "A fome fica", "Morrer na rua" e "Os meus respeitos" - evidenciará a realidade de muitos oprimidos, de cidadáos que vivem em constante abandono, à margem do socius. Para tanto, os ensinamentos do filósofo italiano Giorgio Agamben (2010), sobre o homo sacer, o poder soberano e a vida nua, serăo entrelaçados aos versos do poeta carioca para fundamentaçâo teórica do texto.
\end{abstract}

Palavras-chave: vidas nuas; estado de exceçâo; Felipe Fortuna; O mundo à solta.

ABSTRACT: This paper aims to analyse some poems from "O mundo à solta", by Felipe Fortuna, highlighting social thoughts involved in them, through the saga of "vidas nuas" (AGAMBEM, 2010), those who live in a state of permanent exception. A condition of people in permanent status of exclusion, who live in the borders between the human and not-human condition, and who have their beings excluded from fundamental rights. Thus, working with three poems - "A fome fica", "Morrer na rua" and "Os meus respeitos" - we will show the reality of many oppressed ones, citizens who live in daily neglecting, beyond the borders of socius. For that, teachings of Italian philosopher Giorgio Agambem (2010) about homo sacer, sovereign power and naked life will be connected to the verses by the carioca poet for the text's theoretical background.

Keywords: vidas nuas; state of emergency; Felipe Fortuna; O mundo à solta.

1 Mestra em Letras pela Universidade Federal do Espírito Santo. Atualmente é servidora pública federal, atuando como coordenadora dos cursos de pós-graduaçăo do IFES.E-mail: luzimaracordeiro@gmail.com

2 Doutora em Letras pela Universidade Federal do Espírito Santo (UFES). Atualmente, Diretora de Ensino do Instituto Federal do Espírito Santo (IFES/Campus Colatina).E-mail: elizabetecaron@yahoo.com.br 


\section{O POETA E SUA LÍRICA}

A lírica de Felipe Fortuna estreou na segunda metade do século XX, em 1986, com a publicaçăo de Ou vice-versa e, desde entăo, sua produçăo literária vem florescendo bastante. O escritor, no trânsito do século passado a este, lançou diversos livros de poesia, crítica literária, ensaio, memorialística, literatura infantil e, inclusive, volumes de traduçăo.

Como poeta, o crescimento de Fortuna é visível. Ele recebeu avaliaçôes positivas desde o lançamento de Ou vice-versa, quando Félix de Athayde afirmou: "O livro é um precipício para o alto: porque todo bom poeta constrói precipícios. Do alto de muitos poemas de Felipe Fortuna, o leitor cai, esborracha-se, descobrindo que é apenas um homem entre tantas coisas: um ladrâo que 'encontra o roubo já pronto'" (ATHAYDE, 1987, [s.p.]).

Dos "precipícios" (livro de poemas) construídos por Felipe Fortuna, o escolhido por nós, para ser o corpus deste trabalho, foi $O$ mundo à solta, vindo a lume no ano de 2014. Essa obra nos revela o estilo poético de Fortuna. O escritor carioca é sagaz, pois colhe a matéria viva de seu ofício de diplomata, registrando os acontecimentos do mundo por meio de uma linguagem poética com marcas referenciais. Dentro desse aspecto, enfatiza nâo a prevalência de uma lírica voltada apenas para a perícia técnica do verso (que possui), mas também, como assinalou Silviano Santiago no prefácio de 0 mundo à solta, uma realizaçăo capaz de "[...] guardar na memória poética os processos em aberto do século XXI" (in FORTUNA, 2014, s/p) - processos que, por certo, săo amplos: coletivos, sociais, civilizacionais.

Tais processos apontam para uma característica associada ao autor e à literatura moderna: o fato de ser ele um poeta urbano, em uma tradiçấo que remonta ao Baudelaire de As flores do mal, célebre cantor de Paris: "Fourmillantcité, "Fourmillantecité, citépleine de rêves, / Oùlespectreenpleinjourraccrochele passant!"3. Sendo assim, a arte poética de Fortuna é ferramenta indispensável para o processo de "queda" do leitor atento, cuja subjetividade, inserida na realidade social, encontra-se com o precipício poético de $\mathrm{O}$ mundo à solta, que provoca a queda da alienaçâo e da acomodaçấo dos homens atuais.

O leitor, esse ladrăo e também passante, em meio à "cidade a fervilhar", encontra-se com a literatura que "[...] em lugar de excluir as experiências vividas, [...] faz descobrir mundos que se colocam em continuidade com essas experiências e permite melhor compreendê-las [...]" (TODOROV, 2009, p. 23-24). Fortuna amplia o universo do interlocutor de sua obra, incitando-o a imaginar outras formas de concebê-lo e organizá-lo, ao revelar uma maneira mais dilatada de se enxergar o mundo.

O autor carioca, assim, nos brinda com uma arte viva, nova. Contudo, năo nos confundamos, “O Novo năo é uma moda, é um valor [...]" (BARTHES, 1987, p. 53). Nâo estamos, dessa forma, discutindo modismos, mas a preocupaçáo de um escritor que produz poesia com outros interesses, para além dela mesma. Caso contrário, seu fazer poético seria oco, "beletrista". Fortuna, assim, tem como preocupaçáo principal o que Eliot

3 Na traduçāo de Ivan Junqueira: "Cidade a fervilhar, cheia de sonhos, onde / O espectro, em pleno dia, agarra-se ao passante!" (BAUDELAIRE, 1985, p. 330-331). 
evidencia em sua obra De poesia e poetas, quer seja, a transmutaçăo de sua experiência e de seu pensamento em um fazer poético relevante, que esteja imerso nos problemas do seu tempo (ELIOT, 1991, p. 158). O mundo à solta está imergido na contrariedade, na diversidade do hodierno. Vejamos...

\section{O MUNDO À SOLTA}

O sexto livro de versos de Fortuna, O mundo à solta, compila uma série de poemas de caráter bastante social. Os poemas estâo organizados em três seçôes: "Sobrecarregado", "Idas \& voltas a Londres" e "Os outros assuntos". Conforme o título da primeira parte revela, os poemas ali inseridos explicitarăo questóes inerentes à vigilância eletrônica, às armas químicas, ao comércio de armamentos, ao racismo, aos drones, ao terrorismo, ao combate à fome, ao tráfico humano, ao Guantánamo. Na segunda e terceira parte, o rememorar dos espaços habitados pelo poeta e o perene nomadismo de sua vida se dăo a ver.

Por tudo isso, obra revela a sensibilidade política e poética do diplomata em um mundo que está à beira do descontrole completo, mesmo em um tempo que vive sob a égide (ou tăo só o desejo) da sociedade do controle. Contudo, boa parte desse controle social mais civilizado foi perdida. Năo sem motivo, mas pelo fato de os problemas estarem "à solta" pelo planeta, como nos afirma Silviano Santiago, ao apresentar o livro:

À mesa da poesia, Felipe Fortuna recebe o mundo aberto e faminto, no meio da carnificina humana e do desatino cósmico. "O mundo se vasculha me vasculha. / Nâo exagero." Atacado, o hospedeiro contra-ataca. Felipe clica de repente e sucessivamente o mundo à solta, como se fosse a lente Panoscan que permite aos peritos da NYPD captar imagens em 360 graus das cenas de crime (SANTIAGO, s/d, s/p).

Esse mundo entregue à sorte do destino é denunciado por um autor que sempre teve a dimensâo política presente em sua vida. Em $O$ mundo à solta, Fortuna elabora poesia nâo engajada (em um sentido mais comum, mais "demagógico" do termo, com o qual implica), mas decididamente social (ou seja, mergulhada na problemática da globalizaçấo). Em turbulência, o planeta se transformou na temática central do artista, tal como, muitas décadas antes, a Espanha se tornara um dos assuntos fundamentais do também poeta diplomata (igualmente sem polidez hipócrita na língua) Joâo Cabral de Melo Neto.

Logo, 0 mundo à solta é um livro que aborda a situaçăo do planeta, constituído de textos que, conforme afirma o poeta, "[...] refletem mais o meu espanto diante de um mundo que nos atropela" (FRANCISCO, 2014, p. 8). Desse modo, o volume em causa trata, em seus versos de cunho político, dos problemas vinculados ao mundo todo, vistos pelo olhar de alguém perplexo com a violência do (no) planeta.

Para além de efeitos estéticos evidentes - ritmo, sonoridade, aspecto gráfico e visual -, Fortuna efetua em sua lírica uma comunicaçăo ético-política. Isto se dá pelo fato de que ele náo se prende à tônica da palavra de ordem maniqueísta, ou seja, "[...] nâo existem personagens ou governantes políticos a serem alçados ao poder ou a serem destruídos" (FRANCISCO, 2014, p. 8). Segundo Fortuna, os seus poemas possuem um tom de impessoalidade, isto é, uma "projeçâo globalizada" (FRANCISCO, 2014, p. 8). 
A fim de evidenciar tal afirmaçăo, focaremos em três composiçôes de Fortuna - "A fome fica", "Morrer na rua" e "Os meus respeitos" -, sendo que o nosso olhar se voltará para a saga das "vidas nuas", que vivem em estado de exceçăo permanente. Com esse intuito, os ensinamentos do filósofo italiano Giorgio Agamben sobre o assunto serâo aqui abordados.

\section{VIDAS NUAS EM UM “ MUNDO À SOLTA”}

Os trabalhos de Agamben ganharam notoriedade no cenário acadêmico, após a publicaçấ, no ano de 1995, da primeira ediçấo de Homo sacer: o poder soberano e a vida nua, que inicia o ciclo do seu projeto intelectual. Nesta obra, o escritor define o homo sacer como sendo o indivíduo que vê os seus direitos fundamentais retirados pelo soberano, que passa a ter arbítrio de vida e morte sobre ele, situando-o em uma zona de indiferença, de abandono completo. Além disso, "O homo sacer é, de fato, insacrificável e pode, todavia, ser morto por qualquer um" (AGAMBEN, 2010, p. 112). Tal ser, para Agamben, é uma verdadeira vida nua, sujeitada a um poder de morte, encontrando-se desprovida de tudo e, assim, caracterizável por dois traços: a "matabilidade" e a "insacrificabilidade".

Essa vida sacra, sem direitos resguardados, vive no entre-lugar, um espaço que evidencia a sua absoluta exceçâo. Sem localidade, acaba por revelar o que nos aclara Walter Benjamin: "A tradiçâo do oprimido nos ensina que o estado de exceçâo em que vivemos é na verdade a regra geral" (BENJAMIN, 1994, p. 226). Portanto, encontra-se incluído por meio da exclusăo. O que temos "[...] hoje diante dos olhos é, de fato, uma vida exposta como tal a uma violência sem precedentes, mas precisamente nas formas mais profanas e banais" (AGAMBEN, 2010, p. 113).

Agamben utiliza-se da distinçâo feita pelos gregos entre zoé e bíos, a fim de melhor explicitar em o que consistiria uma "vida nua". O pensador ressalta, entăo, que ambos os termos nomeiam o que, atualmente, denominamos apenas "vida"; no entanto, zoé representava "[...] o simples fato de viver comum a todos os seres vivos (animais, homens ou deuses) e bíos [...] indicava a forma ou maneira de viver própria de um indivíduo ou de um grupo" (AGAMBEN, 2010, p. 9).

A "vida nua" é vista pelo filósofo italiano como zoé, simples ato de viver, destituído de qualificaçâo política. E, segundo o mesmo, a politizaçâo da "vida nua" foi o marco fundador da modernidade, enquanto categoria constituinte da estrutura política do Estado (AGAMBEN, 2010, p. 12). O que define um homo sacer é, todavia, a condiçâo de viver uma exclusăo dupla: religiosa e jurídica, e o fato de estar constantemente exposto à violência, já que pode ser morto sem que isso constitua homicídio ao autor do ato. Sendo assim, Agamben faz uso da figura do homo sacer, a fim de explicitar a ideia de "vida nua".

Na referida figura do homo sacer encontramos, assim, a vida capturada pelo abandono, pois, ao ser decretado como sacer, o homem era despojado de todos os seus direitos, passando de pessoa humana para um simples animal, uma vida exposta ao poder soberano, uma existência que "Năo sabe se vai escapar", conforme podemos observar nos versos de "A fome fica" (sem transformá-los em ilustraçâo simplista da conceituaçăo de Agamben): 


\section{A FOME FICA}

Acordar. A comida nâo dá.

Andar, andar sem comer.

O sol a pino e a visăo ao redor

se enroscam famintos.

Nâo sabe se vai escapar:

se falta alimento, falta até o ar.

Mais tarde vai dormir, a morte dentro.

Um tambor oco bate no corpo

um tombo, um soco só

um filete.

Amanhă abre os olhos

mas já foi despejado.

No pátio, vazio, ficou

sem móveis, o banheiro

trancado, os canos sem água:

os músculos nem se agarram

aos ossos,

os ossos podem até sobrar,

mas isso é tudo.

Năo há mais.

(FORTUNA, 2014, p. 67)

O poema "A fome fica" revela a imagem de uma exclusăo generalizada, em que os indivíduos, pela via da miséria social, vivem um cotidiano de abandono, no qual "Amanhá abre os olhos / mas já foi despejado", como se em um constante estado de exceçăo. A ideia da exceçăo, criada, originalmente, para servir como instrumento a ser usado nos momentos de crise, passa a remeter a algo que ocorre com frequência - e o texto de Fortuna capta uma das suas possíveis ocorrências. Logo, "[...] a exceçăo se torna em todos os lugares a regra, o espaço da vida nua, situado originariamente à margem do ordenamento [...]" (AGAMBEN, 2010, p. 16).

Ao seu modo, "A fome fica" enfoca a "vida nua" teorizada pelo pensador, a precariedade de um ser que "Náo sabe se vai escapar: / se falta alimento, falta até o ar". Os versos retratam uma vida de mínguas, onde "os ossos podem até sobrar, / mas isso é tudo. / Nâo há mais". E, realmente, nâo há nem qualidade política, pois é uma mera vida, de seres que "se enroscam famintos". Aqui notamos zoé, năo bíos. Precariedade extrema, nâo direitos mínimos. 
Sabe-se que, por força da sua configuraçâo estética, uma obra de arte pode alcançar algum teor de universalidade. Ilustrando a carência máxima do ser humano, "A fome fica" revela o poder de, ao menos metonimicamente, representar todas as vidas nuas - e estas, conforme recorda Agamben, brotam nas democracias contemporâneas, na figura dos famintos, marginalizados, refugiados, ou seja, de todas as pessoas destituídas dos seus direitos jurídico-políticos - ou como bem argumenta Luís Eustáquio Soares:

Toda vida nua, portanto, nunca é ela mesma, isoladamente, seja porque se constitui como acúmulo de vidas nuas, de estados de exceçăo precedentes; seja porque, por consequência, a si mesma se inscreve como a contraparte do soberano igualmente acumulado de soberanias passadas (SOARES, 2014, p. 27-28).

Na lírica brasileira, um momento dramático de figuraçăo do homo sacer (obviamente antes que o conceito fosse lançado por Agamben) aparece no poema "O bicho", do livro Belobelo, de Manuel Bandeira:

\section{O BICHO}

Vi ontem um bicho

Na imundície do pátio

Catando comida entre os detritos.

Quando achava alguma coisa,

Nâo examinava nem cheirava:

Engolia com voracidade.

O bicho náo era um căo,

Năo era um gato,

Năo era um rato.

O bicho, meu Deus, era um homem.

(BANDEIRA, 1986, p. 179)

Aqui, como em "A fome fica", há até um "pátio". Este năo é suficiente para revelar conexâo intertextual entre os dois poemas, mas o detalhe de referencialidade urbana, presente em ambos, merece atençâo comparativa. Retomemos, entăo, os versos dos dois poemas que explicitam o vocábulo: "No pátio, vazio, ficou/sem móveis, o banheiro" (FORTUNA) e "Vi ontem um bicho/Na imundície do pátio" (BANDEIRA).

Nos versos de Fortuna, o pátio, além de estar vazio, está sem "móveis". Esse fato nos 
chamou a atençấo, pois o mobiliário tem forte referencialidade com o ambiente privado e individual. Mas estar na rua é o mesmo que estar desnudado. Săo espaços antagônicos. No aconchego do lar, do espaço privado, individual o ser tem sua identidade e açóes validadas, como poder alimentar-se direito, dormir adequadamente e acordar seguro de estar em um lugar que é seu e o protege dos olhos da coletividade. Mas no poema de Fortuna o indivíduo "já foi despejado", ou seja, por viver à margem da sociedade, estar literalmente na rua, encontra-se desprovido de seus direitos básicos como comer, dormir e acordar, por exemplo. As condiçôes de vida, nesse caso, animalizam-no.

Antropomorfizado, ironicamente, năo se assemelha nem a um căo nem a um gato. Isso pelo motivo, talvez, desses dois tipos de animais constituírem, de alguma forma, laços com o espaço privado e individual, uma vez que muitos fazem parte das famílias e das relaçóes de carinho estabelecidas. Mas o bicho tampouco é um rato. Trata-se, entăo, de um animal totalmente insignificante, despresível.

Desprovido de identidade, em meio à multidăo e à "visâo ao redor", esse indivíduo é invisibilizado. Nâo sem motivo, a estranheza e o incômodo do eu lírico no poema de Bandeira, ao notar um "ser humano" procurando algum tipo de alimento no lixo, entre os "detritos".

A arte literária de Fortuna e de Bandeira, ao explicitar a verossimilhança com o real, a predominância do cotidiano, a indignaçáo com a realidade humana, a exclusâo e o abandono, retrata a pobreza e a marginalizaçăo de muitos, na luta pela sobrevivência. Dessa forma, expóe a sociedade desigual em que vivemos, fazendo-nos refletir sobre ela.

Tais vidas, assim, ao serem privadas dos seus direitos, representam a exceçâo soberana, configurando o homo sacer, ou seja, um ser que apenas a partir da exceçáo consegue relacionar-se politicamente (o que é um modo de nâo se relacionar com um mínimo de sucesso). A vida nua é, desse modo, produzida por relaçōes históricas em que o poder soberano "[...] decide sobre o estado de exceçâo", como também tem ele a capacidade de "[...] decidir qual vida possa ser morta sem que se cometa homicídio [...]" (AGAMBEN, 2010, p. 138).

A presença da morte aqui, mesmo que năo se saiba, é corriqueira, resultado do intenso poder que determina a sobrevida, pois, "Na biopolítica moderna, soberano é aquele que decide sobre o valor ou sobre o desvalor da vida enquanto tal" (AGAMBEN, 2010, p. 138). A "matabilidade" e "insacrificabilidade" săo inerentes às vidas de todos os que insistirem em se fazer presentes portando tal condiçăo de homo sacer. No texto a seguir, Fortuna capta mais um caso dessa condiçấo: 


\section{MORRER NA RUA}

O morador de rua

morre incandescente

na rua:

há quem pretenda

alternativamente

enterrá-lo vivo

nas areias de Ipanema

(festa de sol,

uma calma de verăo).

O morador de rua

futura tocha

mas agora preso à margem:

decanta na sarjeta

encosta no poste escorrega

se cobre com a calçada

completa o meio-fio

é atingido em cheio

deambulante

pela pedra portuguesa

pelo paralelepípedo.

Nunca marcou, por ironia,

encontro na esquina:

se entorpece ao sol dos bueiros

pisa pleno nas grades

do cruzamento.

Outra forma de morar morrer

é dormir ao relento.

Mas o dia termina e tem pressa

de vê-lo passar

rumo a outra rua, menos aqui

aqui se paga imposto.

(FORTUNA, 2014, 15-16)

É fato: a lírica de Fortuna evidencia a despersonalizaçāo do indivíduo. 
O ser humano é animalizado (como nos versos de Bandeira, antes citados). Adquire estatuto de bicho, de coisa, algo sem valor que pode ser facilmente descartado.

Imersa na indiferença existencial, essa metamorfose às avessas, retrata igualmente a ideia de "vida líquida", problematizada por Zygmunt Bauman, ou seja, uma vida precária envolta em incertezas constantes.

Sendo assim, "A vida na sociedade líquido-moderna é uma versăo perniciosa da dança das cadeiras, jogada para valer. O verdadeiro prêmio nessa competiçấo é a garantia (temporária) de ser excluído das fileiras dos destruídos e evitar ser jogado no lixo" (BAUMAN, 2007, p. 10). No lixo estâo a "Morrer na rua", como bem nos aclara Fortuna no seu poema, os "invisibilizados" pela sociedade de controle em que vivemos.

A morte em vida, outro mal da sociedade líquida, é exposta pelo poeta: "O morador de rua / morre incandescente / na rua: / há quem pretenda / alternativamente / enterrá-lo vivo / nas areias de Ipanema / [...] / Outra forma de morar morrer / é dormir ao relento". Sendo, desse modo, "O morador de rua / futura tocha". Um desprovido de voz pelo simples fato de náo representar o paradigma desejado pela sociedade capitalista, que nâo se cansa de colocar ao rés do châo aquele que "[...] agora preso à margem: / decanta na sarjeta / encosta no poste escorrega / se cobre com a calçada / completa o meio fio". Literalmente, ao nível da rua, o desvalido náo tem como ser um homem de sucesso, como a sociedade, em sua liquidez, tanto almeja. Afinal, ele deve caminhar "[...] rumo a outra rua, menos aqui / aqui se paga imposto". Neste derradeiro verso vemos uma referência classicista, assumida pelo eu lírico: as pessoas que pagam mais impostos pertencem, em geral, às classes médias e aos estratos dominantes do edifício social.

A prevalência da morte sobre a vida é destacada nos versos: "O morador de rua / morre incandescente". Uma morte que ocorre, inclusive, em vida, do indivíduo que existe "[...] preso à margem: / decanta na sarjeta / encosta no poste escorrega / se cobre com a calçada / completa o meio-fio", pois ele representa, por via da arte, todas as vidas nuas, aquelas em que o óbito é o elemento mais evidente, no contexto dessas vidas perenemente expostas ao desafio de sobreviver.

Eis, assim, mais uma representaçăo da presença da morte, de certa condiçăo humana (alegoria dos marginalizados), do próprio curso de vidas de mínguas. O morador de rua simboliza uma trajetória dura e seca de luta pela sobrevivência.

A linguagem utilizada pelo poeta traz à tona um panorama de vidas abandonadas, expostas ao acaso, vazias de sentido político, pertencentes a um mundo de indiferença. Nesse contexto, elas equivalem ao homo sacer, pois, desprovido dos meios de produçáo, ficam submetidas ao poder soberano (que pode ser o Estado moderno, mesmo uma prefeitura) - ou de quem pretenda "enterrá-lo vivo". Isto porque o itinerário do morador de rua é uma verdadeira via-crucis. A batalha travada na luta pela sobrevivência, apresentada no poema "Morrer na rua", explicita as desigualdades sociais, ao denunciar a realidade cruel vivenciada pelo seu morador, dado a ver no poema. Vejamos mais um trabalho em que a questăo encontra eco: 


\section{OS MEUS RESPEITOS}

Àquele que viu tudo

e por ter visto

tornou-se arquivo

năo se esquivou

cravaram quinze tiros.

Àquela faxineira, andava

a pé, seguida

estuprada (blusa

curta decotada) dois rapazes

(um deles, mau hálito)

mas rumo ao trabalho

no mesmo horário.

Àquele bebê

pijama azul, menino

deitado no berço

chocalho ao lado

sem choro, sem vacina

ainda assim

bala perdida.

Àquele no ônibus

o jornal descreveu:

trabalhador, mas afoito

sem sentir o assalto

morreu no assento

no bolso uns trocados.

Àquele pedestre

passageiro sem hora

ponto fora da curva

agora defunto: atropelou-o 
todo o coletivo

parador.

Àquele sem pressa

ao desapartar a briga

no meio da festa

facada:

a família o enterra

ou entâo o crema.

(FORTUNA, 2014, p. 13-14)

"Os meus respeitos" - outra composiçăo de O mundo à solta - apresenta, pois, exemplos dramáticos de vidas desconsideradas, vidas nuas, como a da "[...] faxineira, [...] / a pé, seguida / estuprada [...]", a do "[...] bebê / sem choro, sem vacina / ainda assim / bala perdida", ou a daquele "trabalhador [...] / [que] morreu no assento", ou mesmo a do "pedestre [...] / agora defunto: [...]" ou a daquele que "[...] sem pressa / ao desapartar a briga / no meio da festa / facada".

As existências mencionadas nos versos de Fortuna simbolizam as que Agamben caracteriza como modelos de vidas nuas, pois săo colocadas à margem, desprotegidas, supérfluas, expostas ao abandono e à morte que ocorre violentamente: "cravaram quinze tiros" ou "facada".

Ao revelar os sintomas do empobrecimento e da dissoluçăo das relaçôes devido ao exercício do poder, Fortuna expóe a experiência coletiva potencialmente perigosa da era da liquidez, já que nela qualquer um pode ser liquidado: “Àquele bebê / pijama azul, menino / deitado no berço / chocalho ao lado / sem choro, sem vacina / ainda assim / bala perdida". Este último detalhe tem famigerada relevância em diversos estados brasileiros, inclusive o Rio de Janeiro natal do autor.

Constituídos por relaçóes de poder, os modos de pensar, de agir e de sentir do sujeito se efetivam vincados em determinadas regras de controle, sem que haja certezas, tampouco segurança. Por esse motivo, as relaçōes estabelecidas sâo líquidas e os indivíduos nâo podem firmar nada além de relaçôes com essa liquidez.

\section{ALGUMAS CONSIDERAÇÕES}

Os três poemas de $O$ mundo à solta, analisados neste trabalho, revelam, de modo contundente, a saga das vidas nuas na atualidade, em um mundo que gira e gira e gira, mas năo muda a rota, pois mantém o perene estado de exceçáo dos menos favorecidos. Claro, o movimento aqui assinalado pelo verbo năo é apenas físico, de um corpo celeste no espaço, rodando em volta de si mesmo: trata-se, antes, de ressaltar como as coisas, as pessoas, "as vidas nuas", os fatos estáo postos, como tudo se repete. Seria um eterno rolar de Sísifo? O castigo da minoria, que paradoxalmente é maioria, é permanecer 
em "eterno" em estado de exceçăo, ser "vida nua"? Significativamente, nenhuma das três composiçóes consegue apresentar uma visăo um pouco mais otimista dos eventos sociais do orbe em que habitamos. Para recordar tal aspecto, que se repete ao longo das páginas do livro discutido, relembremos os títulos dos poemas analisados: - "A fome fica", "Morrer na rua" e "Os meus respeitos". Acrescido a eles, outra tríade se apresenta ao longo do livro, todas com a mesma rotaçăo, quer dizer, título: "O mundo gira". A saber:

\section{O MUNDO GIRA}

Excomungados, banidos.

Escravos e deportados.

Refugiados, sumidos,

expulsos, expatriados.

(FORTUNA, 2014, p. 75)

\section{O MUNDO GIRA}

Aqui năo pode: é exclusivo.

Favor náo pisar na grama.

Vem para o gueto: pode passar

pela entrada de serviço.

(FORTUNA, 2014, p. 76)

\section{O MUNDO GIRA}

Os franceses, năo. Tampouco os suíços

que, como os belgas, tăo logo se livram.

Os ingleses escapam. Alemăes

têm tudo o que precisam. [...]

(FORTUNA, 2014, p. 79)

Nesse girar, em relaçăo aos três textos analisados e associados, agora com os três de títulos iguais, tăo só destacaremos um pormenor: a possibilidade que, nas máos dos artistas da palavra, os símbolos linguísticos têm de transformar-se em ícones, embora também verbais (PIGNATARI, 1987, p. 156). E isso se efetiva, neste estudo, náo apenas pela existência de três poemas de Fortuna, mas de seis. Isso porque o "O mundo gira à solta".

O autor urbano é impulsionado a escrever sobre algumas realidades responsáveis por uma ampla situaçâo de reiteraçâo de dados negativos, decorrentes das relaçôes de poder de um mundo líquido, em que a produçâo da morte em massa das vidas nuas ocorre como um fruto das condiçóes impostas pelo capitalismo, pelo controle e pela vigilância, enfim, pelo biopoder. 
Impactado com o real em que vive e refletindo sobre os problemas planetários de um mundo que gira socialmente enlouquecido, além da preocupaçâo com a dimensâo estética do seu texto, Fortuna faz da sua lírica, pois, um cantar ético-político. Logo, uma literatura năo "engajada" (panfletária), como ele mesmo afirma, mas, sim, política. Um poeta que, no girar do mundo, também se movimenta e nos coloca em rota de colisăo com nossas verdades.

De encontro a muito do que acreditamos, o choque nos faz enxergar, nos poemas escolhidos para análise, a banalizaçâo tanto da vida quanto da morte dos "bichos". Estes săo desnudados, invisibilizados, esquecidos, ignorados, desprovidos de direitos de cidadania pelo sistema sócio-político das sociedades contemporâneas, no contexto urbano.

Nas cidades, lugares símbolo da marginalizaçâo social, as "vidas nuas" săo barradas pelo filtro do mercado. No quadro de consumidores, em consonância com Baumam (2008), os menos favorecidos, por năo se apresentarem como participantes ativos de condutas sociais adequadas, ou seja, náo se submeterem a si mesmos como mercadorias - estando na moda, por exemplo -, náo săo mostráveis, menos ainda expostos em "vitrines".

As "vidas nuas", os "cidadăos falhos" (BAUMAN, 2008, p.58), săo deixados no lado oposto do filtro mercadológico: o do nâo consumidores. Encontram-se abaixo da linha da pobreza. Sâo os "bichos", os "moradores de rua", os "excomungados, banidos, escravos e deportados, refugiados, sumidos, expulsos, expatriados" que, considerados seres torpes, sâo estigmatizados, devido ao fato de nâo serem participantes da "cultura".

Essa indiferença permite somente uma passagem para esses indivíduos: a "entrada de serviços". A absorçâo pelo filtro do mercado, desse modo, ocorre com muita intensidade apenas para os mais aptos e verdadeiramente autorizados a operar nele. Eis a banalizaçấo da vida do indivíduo moderno, o estado de exceçăo permanente, revelado nos poemas de Fortuna, explicitando o que usualmente é desconsiderado pela sociedade contemporânea: a consideraçăo, a solicitude, a solidariedade, a empatia, a interdependência de todos os seres humanos.

Os poemas de Fortuna năo sâo unicamente para o deleite do leitor. Eles convidam à análise do funcionamento das relaçôes sociais, ao mostrar, sem adornos e sem clemência, os problemas reais e hodiernos das "vidas nuas". Além disso, o leitor atento tem a possibilidade de aguçar o olhar e, quem sabe, ter seu momento epifânico: o resgate dos sentimentos humanos, do enxergar humanizado.

A poética de Fortuna, ao revelar a saga das "vidas nuas" em 0 mundo à solta, explicita o ponto de intervençâo ofertado a nós leitores: o social. Imersos nos poemas podemos decifrá-los, aceitá-los ou năo, mas, acima de tudo, nos transformar. Eles repercutem em nós. A arte de Fortuna permite-nos, estimulados por novas vivências, criar novos caminhos, configurar sentidos antes inexistentes. Enfim, nos possibilita entrar em contato com a vida, com a história da contemporaneidade e, o melhor, nos inquietar e desestruturar nossas bases, impostas pela sociedade que tanto nos aliena. 


\section{REFERÊNCIAS}

AGAMBEN, Giorgio. Homo sacer: o poder soberano e a vida nua I. Belo Horizonte:UFMG, 2010.

ATHAYDE, Félix. "Ou vice-versa". Jornal de Letras, Ano XXXVIII, no. 432, Suplemento Letras \& Artes, Ano II, no. 13, dez. 1987. Disponível em: <http://www.felipefortuna.com/ resenha-de-felix-de-athayde/>. Acesso em: 20 janeiro. 2019.

BANDEIRA, M. Poesias completas. 4. ed. Rio de Janeiro: José Olympio, 1986.

BARTHES, Roland. O prazer do texto. Trad. J. Guinsburg. Săo Paulo: Editora Perspectiva, 1987.

BAUDELAIRE, Charles. As flores do mal. Trad., intr. e n. Ivan Junqueira. Rio de Janeiro: Nova Fronteira, 1985.

BAUMAN, Zygmunt. Tempos líquidos. Trad. Carlos Alberto Medeiros. Rio de Janeiro: Jorge Zahar, 2007.

BAUMAN, Zygmunt. Vida para consumo: a transformaçăo das pessoas em mercadorias. Rio de Janeiro: Zahar, 2008.

BENJAMIN, Walter. Magia e técnica, arte e política: ensaios sobre literatura e história da cultura. São Paulo: Brasiliense, 1994.

ELIOT, T. S. De poesia e poetas. Trad. Ivan Junqueira. Sáo Paulo: Brasiliense, 1991.

FRANCISCO, Severino. Poesia no caos globalizado - entrevista com Felipe Fortuna. In: Correio Braziliense. Suplemento Diversâo \& Arte, p. 8, quinta-feira, 30 de outubro de 2014.

FORTUNA, Felipe. O mundo à solta. Rio de Janeiro: Topbooks, 2014.

PIGNATARI, Décio. Semiótica e literatura. 3. ed. Sāo Paulo: Cultrix, 1987.

SANTIAGO. Silviano. "Apresentaçăo de Silviano Santiago". Disponível em: <http://www. felipefortuna.com/apresentacao-de-silviano-santiago/>. Acesso em: 17 fev. 2017.

SOARES, Luís Eustáquio. A sociedade do controle integrado. Vitória: Edufes, 2014.

TODOROV, Tzvetan. A literatura em perigo. Trad. de Caio Meira. Rio de Janeiro: DIFEL, 2009. 